\title{
EXPERIMENTAL TECHNIQUES AND NUMERICAL MODELS TO DETECT POLLUTANT EMISSION IN THE TRANSPORT SECTOR
}

\author{
GUIDO MARSEGLIA ${ }^{1}$, CARLO MARIA MEDAGLIA ${ }^{1}$, FRANCISCO ALONSO ORTEGA ${ }^{2}$, \\ JUAN A. MESA ${ }^{2} \&$ DAVID CANCA ${ }^{3}$ \\ ${ }^{1}$ Università degli Studi Link Campus University, Rome, Italy \\ ${ }^{2}$ Departamento de Matematica Applicada II, Universidad de Sevilla, Spain \\ ${ }^{3}$ Departament of Industrial Engineering and Management Science, Universidad de Sevilla, Spain
}

\begin{abstract}
In recent years, the growth of fossil fuel use and greenhouse gases emissions (GHGs) has been promoted by the population increase and development of the industry sector. Due to the increasing attention towards the effects of climate changes on quality of life, recent researches on pollutant formation processes have been developed in different sectors, especially in transportation. The last emission standards on pollutants impose limits on the dimensions and on the particle number of the particulate matter emissions, because of the highly dangerous effect on human health. To fight high concentrations of particulate matter (PM) emissions, a wide number of studies are addressed towards the definition of the most important parameters in effective production of particulate matter, especially in spark ignition engines. Physical processes such as mixture formation, engine operating parameters and fuel chemical properties strongly affect the soot formation in gasoline engines. The heat transfer process between the piston hot surface and the fuel gasoline during the post-injection phase is a key aspect of soot emissions for an engine. This paper is devoted to analyzing the fundamental parameters that are responsible for pollutant formation in the transport sector and the actual experimental and numerical techniques used to predict the environmental impact of engines.

Keywords: climate changes, pollutant, transportation, particulate matter emissions, experimental and numerical techniques.
\end{abstract}

\section{INTRODUCTION}

In current years, the restructuring of the transport sector as a consequence of climate change on human living is assuming a fundamental role [1]-[6]. In 2015, the Member States of the United Nations committed to implement the 2030 Agenda for Sustainable Development. The 17 Universal Sustainable Development Goals (SDGs) consider a wide range of global problems, including the preservation of our environment and life conditions [7]-[10].

In particular, the analysis of performance and pollutant emissions in engines is a key aspect due to the restrictive standards on engines emissions at homologation [9], [11]. Actually, research in the automotive sector mainly investigates the thermofluidynamic and chemical parameters occurring during the injection and combustion phases [12].

Since the 1990s, passenger cars have been endowed with gasoline direct injection (GDI) engines because of their lower fuel consumption with respect to the port fuel injection (PFI) engines [13]. On the other hand, a worrying source of PM today is represented in the GDI engines. Considering the New European Driving Cycle (NEDC), GDI engines present a particulate number concentration 10 times that of PFI [14].

Euro 6 regulations on pollutants also introduce a limit on particle number emission to $6.0 \times 10^{12} \# / \mathrm{km}$ in Euro $6 \mathrm{~b}$ in 2014 , and $6.0 \mathrm{x} 10^{11} \# / \mathrm{km}$ in Euro $6 \mathrm{c}$, valid from September 2017. The diameter of each particle at the engine exhaust is strongly linked to the residence time in air and to the impact on human health. In June 2014, the World Health Organization considered engine soot ultrafine particles as possible cause of cancers. Cardiovascular and 
pulmonary illnesses and influences on human DNA can be caused by prolonged exposition to $\mathrm{PM}_{2.5}$ [9], [14], [15]. Thus, the study of processes that occur in the combustion chamber is important to better understand which are the parameters that influence the pollutant emissions [11], [16], [17] at the engine exhaust and the possibility to have abnormal combustion occurrence, such as knock [18], [19], thus a decrease in energy performance. Controlling air-fuel ratio, hence fuel injection in direct injection (DI) engines, surely represents an advantage to obtaining a stable, full and clean combustion process development [20], [21]. Due to various mixture formation processes and combustion evolution, the possible particle dimensions and compositions at the engine exhaust are various. In the detailed analysis of injection spray evolution, it is fundamental to take into account the possible impact with solid surfaces, especially if mixture formation occurs during the so-called wall-guided GDI combustion chamber methodology [22], [23]. The deposition of gasoline wall films in the combustion chamber is an important cause of pollutant emissions in engines [24], [25]. The wall piston surface temperature is considered a key parameter, influencing the entire working of the engine [26]. In this perspective, the analysis of the factors that affect the structure and the spatio-temporal development of the spray is fundamental in order to obtain reliable and predictive numerical models. This paper focuses on the state of the art of the main parameters that are responsible for particulate matter emissions and the actual experimental and numerical methodologies considered providing the pollutant formation in engines.

\section{MIXTURE FORMATION PROCESSES IN GDI ENGINES}

Automotive industries are recently addressing a transition from PFI towards direct injection spark ignition (DISI) engines [27]. In PFI configuration, gasoline is injected at a fairly low pressure in the duct of the intake valve; DISI systems allow for the direct injection gasoline in the combustion chamber using high-pressure injectors. Fig. 1 reports a basic scheme of the two different injection methodologies.
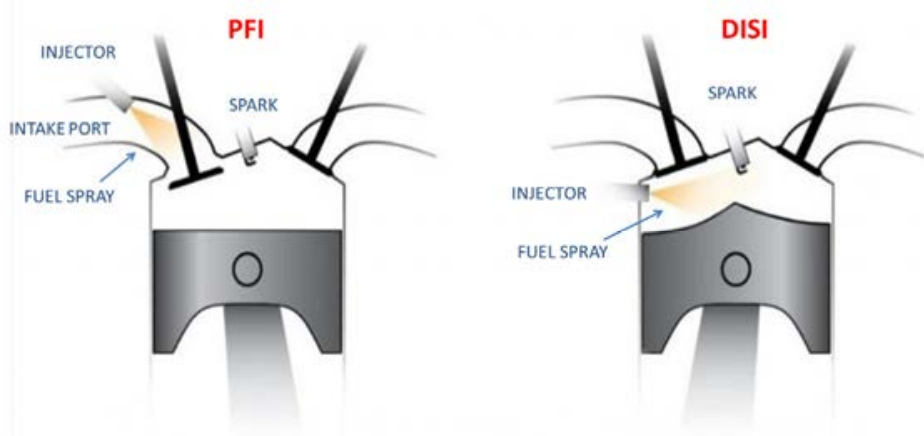

Figure 1: Port fuel injection (PFI) and gasoline direct injection (DISI) configurations [28].

To understand the stratified charge, working the detailed knowledge of mixture formation processes in engines is fundamental [27]. Fig. 2 shows the main different methodologies of obtaining a charge stratification in an engine cylinder [29], [30]. The wall-guided technology provides that fuel spray is addressed towards the piston, which presents a typical shape steering the mixture in close proximity to the spark plug. The richer mixture region is instead addressed toward the spark plug due to the tumble movement of 
the air that comes from the intake ducts in the air-guided configuration. The third possible mixture formation strategy for charge stratification is called spray-guided or jet-guided. In this case, there is a lower distance injector-spark and the gasoline is addressed directly to the spark location.
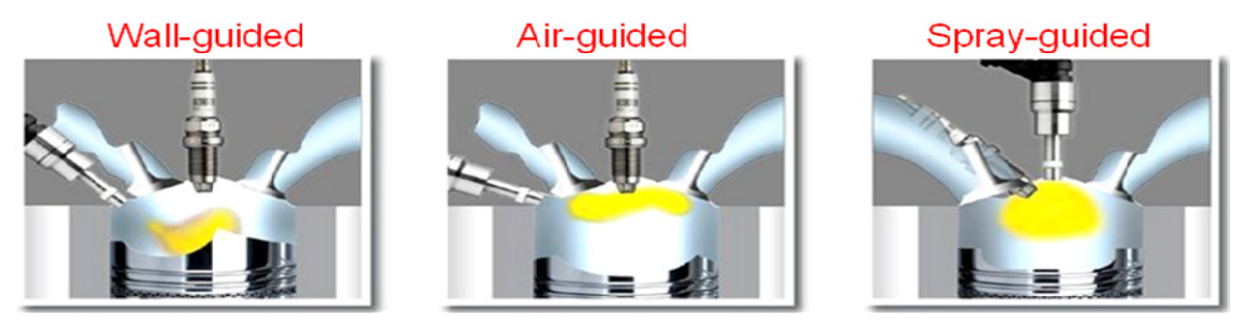

Figure 2: Mixture formation in a GDI engine [29].

\section{PARTICULATE MATTER CONTROL STRATEGIES}

The most common techniques used to reduce particulate emissions in GDI engines are mainly focused on the reduction of soot formation linked to wall-film deposition on the piston surface and on the optimization of pollutants filtration system. Different techniques are used to control the PM formation in the combustion chamber of gasoline engines. An idea of these methodologies proposed by Piock et al. [31] is schematized in Fig. 3.

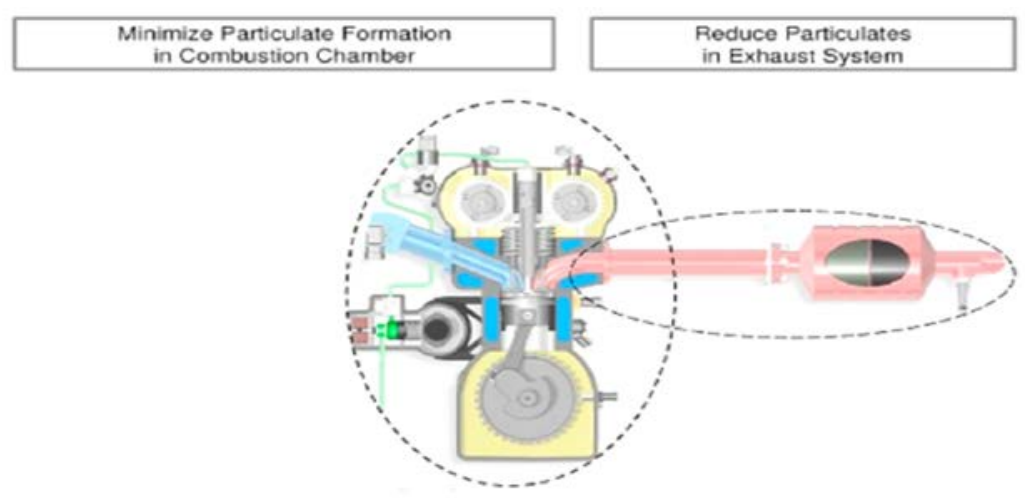

Figure 3: Strategy to control pollutant emissions in engines [14], [31].

Piock et al. [31] underlined the link between the mixture formation process and ultrafine particle emissions. The technical strategy proposed is focused on some parameters linked to the intake system, as valve lift and valve timing, intake air temperature and filling coefficient linked to gasoline injection equipment, try to prevent fuel wall-film deposition, and reach an optimal distribution of air-fuel ratio in the combustion chamber using multi-hole and high-pressure injectors in order to have a better vaporization of fuel in the combustion chamber and lower values of Sauter mean diameter [14]. In fact, pollutant droplets strongly depend on the penetration length and velocity and evaporation process. 


\section{EXPERIMENTAL RESEARCHES}

Today, various techniques for pollutant emissions are based on the analysis of fuel spray evolution [32]. Key parameters of spray evolving during the injection stage as hollow cone and length penetration, can be investigated thanks to detection with high spatial and temporal images. A good accuracy in the pollutant formation prediction can be obtained through the complete and clear knowledge of the evaporation fuel process subsequent to the injection stage. From an experimental point of view, the spray characterization and the air-fuel ratio distribution in the combustion chamber are investigated considering different methodologies as laser-induced fluorescence (LIF) [33]-[36].

The influence of key parameters such as injection timings, piston shapes, and intake flow on the mixture formation process in GDI engines, is analyzed by Kang and Kim [21] through the laser-induced exciplex fluorescence (LIEF) methodology. Air-fuel ratio distribution is strongly linked to abnormal combustion events or pool-flames formation [18]. Previous works [11], [37] underline the experimental details in the analysis of gasoline spray from a wall-guided multi-hole injector and its impact over a hot wall on a real GDI piston. Different operating conditions can be investigated to study the spray/wall interaction and the subsequent gasoline vaporization.

An example of an experimental procedure adopting a piston used during the wall-guided methodology is reported in Fig. 4, in which is evident the piston shaped to avoid the charge stratification. The frequent injectors used in the experimental set-up for GDI engines is the multi-hole injector, because they offer a better fuel nebulization. Generally, a synchronized pulse from an electronic control unit (ECU) starts the spray delivery, and a fast camera is necessary to capture experimental images of the fuel. Zeng et al. [38] underlined the importance of infrared (IR) analysis to study in detail the heat exchange between the fuel spray and the piston considered.

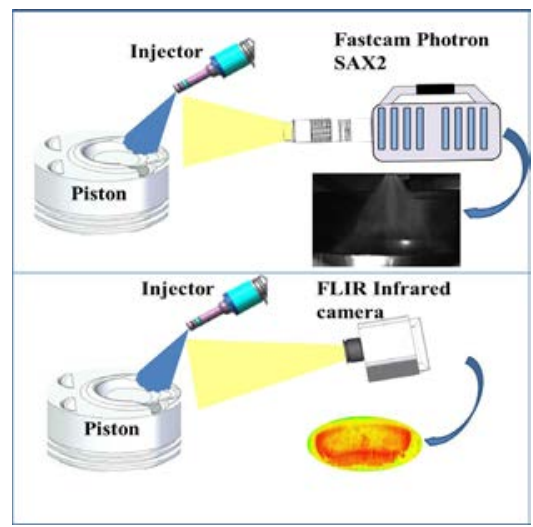

Figure 4: Example of a scheme of an experimental set-up considered in the analysis of fuel wall film deposition [11].

The most important parameters considered in the experimental tests are the duration of injection (DOI), the pressure of injection, and the start of injection (SOI), the inclination of the injector and the distance from the injector nozzle to the piston wall.

In this way, it is possible to study the injection event and the spray behavior after the impact on the piston wall. Another example present in literature of the high speed 
experimental images that are possible to acquire from a multi-hole injector for different events is reported in Fig. 5 [32]. The sequence images refer to different time after the start of the injection (ASOI) at a temperature of $293 \mathrm{~K}$, pressure of 1 bar (injection pulse $1.5 \mathrm{~ms})$. Aleiferis et al. [32] considered the behavior of two different fuels as shown in Fig. 5: the gasoline and the E85 (mixture of $85 \%$ ethanol and 15\% gasoline). They highlighted the effects of different fuels during injection and combustion phases. The collection of this kind of images allows the acquirement of fundamental information about the penetration length evolution, or the spray hollow cone.

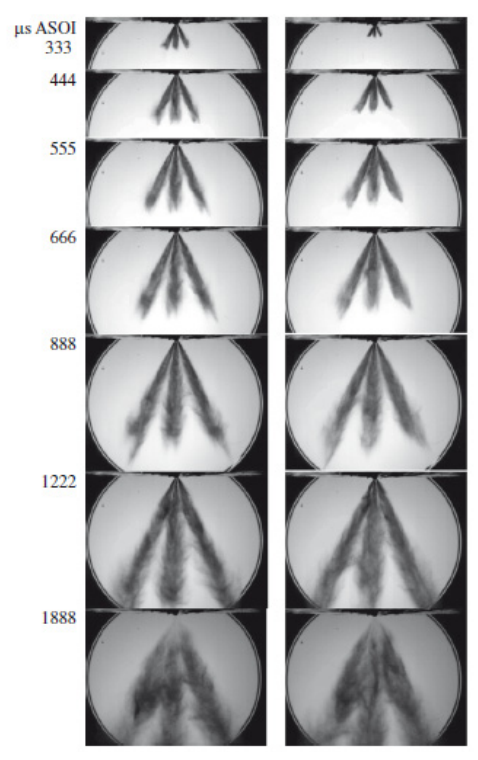

Figure 5: Example of spray evolution images for gasoline (first column) and E85 fuel (second column) [32].

Different techniques are possible to detect the piston temperature, fundamental in the wall deposition phenomena. In recent experimental tests [39], local temperature measurements are detected from thermocouples mounted on the piston wall.

To have a better idea of the phenomena that occur during the post-injection phase, recent experimental researches adopt the IR analysis. By means of an IR camera, after a calibration performed by taking into account the piston material features, it is possible to measure the piston surface temperature distribution.

\section{NUMERICAL MODELS}

The spray model in engines is considered in various researches (for example Sirignano [40]; Fritsching [41]; Loth [42]; Costa et al. [43]; and Catapano et al. [44]). Sprays can be considered specific kinds of two-phase flows, presenting a main direction of liquid state, separated in particles ligaments, and a gas phase as a continuum. Sprays are considered as the result of high-pressure-driven liquid jets conducted in air by means of various injector nozzle holes. The spray atomization produces different liquid snippets, and particles, that can also evaporate. The modeling analysis, based on a detailed assessment of the three-dimensional computational fluid dynamic (3D CFD) studies, compared with the 
experimental tests, can give fundamental information on the fluid-dynamic aspects, in order to obtain better results for energy efficiency optimization and reduction of the pollutant emissions of the engine under study. With respect to 1D, the 3D CFD model allows simulating in detail the engine operating conditions, the injection phase and the combustion evolution [45]. A proper CFD prediction model can reduce the costs and the time used in experiments necessary to study the engine optimization. For these reasons, CFD analysis is frequently used in order to simulate the injection phase.

Concerning fuel wall-film deposition, different models are used such as the Mundo-Sommerfeld, Kuhnke or Senda models in literature, to analyze the spray/wall interaction on the hot piston wall surface [46]-[49]. Between these, one of the most frequently used is the Kuhnke theory. This model is important because it considers the wall temperature during the interaction phenomenon, allowing a better analysis of heat exchange and the energy balance eqn before and after impact. Kuhnke [48] identifies four regimes, influenced from the parameter $\mathrm{K}$ value:

$$
K=\frac{\left(\rho_{d} d_{d}\right)^{3 / 4} u_{d, \perp}^{5 / 4}}{\sigma_{d}^{1 / 2} \mu_{d}^{1 / 4}} .
$$

The identification of the different regimes can be made in the $\mathrm{K}, \mathrm{T}^{*}$ plane, as shown in Fig. 6, where $T^{*}=T_{w} / T_{s}, T_{w}$ being the wall temperature and $T_{s}$ the droplet boiling temperature. The values of $\rho_{\mathrm{d}}, \sigma_{\mathrm{d}}, \mu_{\mathrm{d}}$ are the density, the surface tension and the dynamic viscosity of the gasoline droplet, respectively. $\mathrm{d}_{\mathrm{d}}$ is considered as the average diameter of droplets. The droplet speed normal component to the surface is considered $u_{d}$.

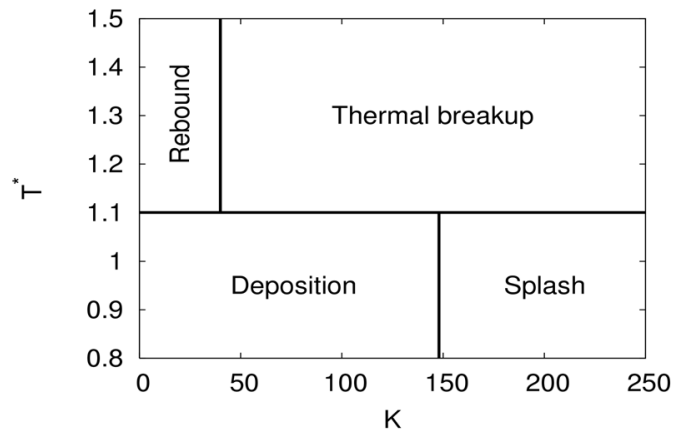

Figure 6: Regime map for spray/wall impact according to Kuhnke [48].

Four different conditions are identified in the Kuhnke model:

- the deposition regime in which it is possible to have wall-film: particles impacting fully attach on the wall;

- $\quad$ in the splashing regime particles are nebulized and after their interaction on the surface can be formed smaller secondary droplets;

- the rebound case, in which there is not wall-film formation, presents a vapor formation between the droplet and the surface that avoids directly the contact and allows reflecting the impacting particles;

- the disintegration of particles in smaller droplets happens during the thermal conditions, in which there is not wall-film deposition. 
The comparison between numerical and experimental researches also helps to have a validation of the numerical model today. In this way, 3D CFD simulation can be fundamental to predict and try to control the pollutant emission formation.

Different simulation codes such as AVLFIRE, OPENFOAM, KIVA, ANSYS FLUENT, STAR CD [50]-[54] are today used to study the spray modelling and the mixture formation in engines.

Catapano et al. [11] provides a better understanding of which technical aspects and physical phenomena are involved in the pollutant emissions processes; for example, the results obtained from a synergic experimental and numerical research developed for DISI engine. Numerical CFD modeling enables the obtainment of additional information at the microscopic level of fuel droplets evolving, such as the droplet diameter.

\section{CONCLUSIONS}

The preoccupation for the effects of climate change on quality of life is addressing actual researches toward the analysis of pollutant formation processes in vehicles. The main parameters that are responsible for PM emissions are considered analyzing actual studies on fuel injection evolution in engines.

Some physical processes taking place in engines are investigated, underlining the benefits of the modern GDI with respect to the PFI engines. This research reviews some important actual experimental and numerical methodologies considered to provide the pollutant formation in engines. Experimental high spatial and temporal images provide important information on the injection phase. The choice of proper numerical model is fundamental to better predict pollutant emissions in an engine.

The comparison between experimental and numerical activity can allow for comparison between the experimental images of the spray characterization in different events and those obtained from numerical models, and also provide better knowledge of phenomena linked to particulate matter emissions such as wall-film deposition on the top piston surface.

\section{REFERENCES}

[1] Ortega, F.A., Piedra-De-La-Cuadra, R. \& Ventura, S., Applying an entropic analysis to locate rapid transit lines in Sprawled Cities. International Journal of Sustainable Development and Planning, 13(4), pp. 626-637, 2018.

[2] Canca, D. \& Barrena, E., The integrated rolling stock circulation and depot location problem in railway rapid transit systems. Transportation Research Part E, 109, pp. 115-138, 2018.

[3] Canca, D. \& Zarzo, A., Design of energy-efficient timetables in two-way railway rapid transit lines. Transportation Research Part B, 102, pp. 142-161, 2017.

[4] Chen, D. \& Sun, J., Fuel and emission reduction assessment for civil aircraft engine fleet on-wing washing. Transportation Research Part D, 65, pp. 324-331, 2018.

[5] Kousoulidou, M., Ntziachristos, L., Mellios, G. \& Samaras, Z., Road-transport emission projections to 2020 in European urban environments. Atmospheric Environment, 42, pp. 7465-7475, 2008.

[6] Noce, T., Rocha da Silva, R., Morais, R., Monteiro Sales, L.C., De Morais Hanriot, S. \& Sodré, J.S., Energy factors for flexible fuel engines and vehicles operating with gasoline-ethanol blends. Transportation Research Part D, 65, pp. 368-374, 2018.

[7] United Nations. Sustainable Development Goals, New York. https://sustainabledevelopment.un.org/sdgs. Accessed on: 7 Sep. 2016. 
[8] Manni, M., Coccia, V., Nicolini, A., Marseglia, G. \& Petrozzi, A., Towards zero energy stadiums: The case study of the Dacia arena in Udine, Italy. Energies, 11(9), p. 2396, 2018.

[9] Marseglia, G., Rivieccio, E. \& Medaglia, C.M., The dynamic role of Italian Energy strategies in the worldwide scenario. Kybernetes, 48(3), pp. 636-649, 2019.

[10] Mendecka, B. \& Lombardi, L., Environmental evaluation of waste to energy plant coupled with concentrated solar energy. Energy Procedia, 148, pp. 162-169, 2018.

[11] Catapano, F., Costa, M., Marseglia, G., Sementa, P., Sorge, U. \& Vaglieco, B.M., An experimental and numerical investigation of GDI spray impact over walls at different temperatures. SAE Technical Paper, 2016.

[12] Garcia, A. \& Monsalve-Serrano, J., Analysis of a series hybrid vehicle concept that combines low temperature combustion and biofuels as power source. Results in Engineering, 1, 2019.

[13] Zhao, H., Advanced Direct Injection Combustion Engine Technologies and Development, vol. I: Gasoline and Gas Engines and vol. II: Diesel Engines, Woodhead Publishing, 2010.

[14] Qian, Y., Li, Z., Yu, L., Wang, X. \& Lu, X., Review of the state-of-the-art of particulate matter emissions from modern gasoline fueled engines. Applied Energy, 238, pp. 1269-1298, 2019.

[15] Nezisa, I., Biskosb, G., Eleftheriadisd, K. \& Kalantzia, O.I., Particulate matter and health effects in offices - A review. Building and Environment, 156, pp. 62-73, 2019.

[16] Desantes, J.M., Garcia-Oliver, J.M., Garcia, A. \& Xuan, T., Optical study on characteristics of non-reacting and reacting diesel spray with different strategies of split injection. International Journal of Engine Research, 2018.

DOI: $10.1177 / 1468087418773012$.

[17] Gehmlich, R.K., Mueller, C.J., Ruth, D.J., Nilsen, C.W., Skeen, S.A. \& Manin, J., Using ducted fuel injection to attenuate or prevent soot formation in mixing controlled combustion strategies for engine applications. Applied Energy, 226, pp. 1169-1186, 2018.

[18] Marseglia, G., Costa, M., Catapano, F., Sementa, P. \& Vaglieco, B.M., Study about the link between injection strategy and knock onset in an optically accessible multi-cylinder GDI engine. Energy Conversion and Management, 134, pp. 1-19, 2017.

[19] Duan, X., Liu, J., Tan, Y., Luo, B., Guo, G., Wu, Z., Liu, W. \& Li, Y., Influence of single injection and two-stagnation injection strategy on thermodynamic process and performance of a turbocharged direct-injection spark-ignition engine fuelled with ethanol and gasoline blend. Applied Energy, 228, pp. 942-953, 2018.

[20] Cavicchi, A., Postrioti, L. \& Scarponi, E., Hydraulic analysis of a GDI injector operation with close multi-injection strategies. Fuel, 235, pp. 1114-1122, 2019.

[21] Kang, J.J. \& Kim, D.J., Effects of piston shapes and intake flow on the behavior of fuel 460 mixtures in a GDI engine. Korean Society of Mechanical Engineers International Journal, 17(12), pp. 2027-2033, 2003.

[22] Su, Y.H. \& Kuo, T.F., CFD-assisted analysis of the characteristics of stratified-charge combustion inside a wall-guided gasoline direct injection engine. Energy, 175, pp. 151-164, 2019.

[23] Banerjee, R. \& Kumar, S. Numerical investigation of stratified air/fuel preparation in a GDI engine. Applied Thermal Engineering, 104, pp. 414-428, 2016. 
[24] Zhang, M., Honga, W., Xie, F., Sua, Y., Liu, H. \& Zhou, S., Combustion, performance and particulate matter emissions analysis of operating parameters on a GDI engine by traditional experimental investigation and Taguchi method. Energy Conversion and Management, 164, pp. 344-352, 2018.

[25] Pei, Y., Qin, J., Li, X., Zhang, D., Wang, K. \& Liu, Y., Experimental investigation on free and impingement spray fuelled with methanol, ethanol, isooctane, TRF and gasoline. Fuel, 208, pp. 174-183, 2017.

[26] Schulz, F., Schmidt, J., Kufferath, A. \& Samenfink, W., Gasoline wall films and spray/wall interaction analyzed by infrared thermography. SAE Technical Paper, 2014.

[27] Marseglia, G. \& Medaglia, C.M.M., Energy efficiency in gasoline direct injection engines. WIT Transactions on the Built Environment, vol. 182, pp. 85-91, 2019.

[28] Still Running Strong. Gasoline Direct Injection Engines Explained. https://stillrunningstrong.com/car-technology/gasoline-direct-injection/.

[29] Sorge, U., Simulazione Multidimensionale ed Ottimizzazione del Processo di Conversione dell'Energia in Motori ad Iniezione Diretta di Benzina. PhD thesis, University Federico II of Naples: Naples, 2013.

[30] Marseglia, G., Knock Onset and Soot Formation in Gasoline Direct Injection Engines: Issues for Future Development. PhD thesis, Istituto Motori \& Parthenope University of Naples: Naples, 2016.

[31] Piock, W., Hoffmann G., Berndorfer, A., Salemi, P. \& Fusshoeller, B., Strategies towards meeting future particulate matter emission requirements in homogeneous gasoline direct injection engines. SAE Technical Paper, 2011.

[32] Aleiferis, P.G., Serras-Pereira, J., Van Romunde, Z., Caine, J. \& Wirth, M., Mechanisms of spray formation and combustion from a multi-hole injector with E85 and gasoline. Combustion and Flame, 157, pp. 735-756, 2010.

[33] Kranz, P. \& Kaiser, S.A., LIF-based imaging of preferential evaporation of a multi-component gasoline surrogate in a direct-injection engine. Proceedings of the Combustion Institute, vol. 37, pp. 1365-1372, 2019.

[34] Liu, Y. Pei,Y., Guo, R., Wang, C. \& Xu, B., Investigation of the liquid fuel film from GDI spray impingement on a heated surface with the laser induced fluorescence technique. Fuel, 250, pp. 211-217, 2019.

[35] Gao, H., Zhanga, F., Zhang, Z., Wang, E. \& Liu, B., Experimental investigation on the spray characteristic of air-assisted hollow cone gasoline injector. Applied Thermal Engineering, 151, pp. 354-363, 2019.

[36] Salvador, F.J., Carreres, M., Crialesi-Esposito, M. \& Plazas, A.H., Determination of critical operating and geometrical parameters in diesel injectors through one dimensional modelling, design of experiments and an analysis of variance. Proceedings of the Institution of Mechanical Engineers, Part D: Journal of Automobile Engineering, 232(13), pp. 1762-1781, 2018.

[37] Catapano, F. Marseglia, G., Sementa, P. \& Vaglieco, B.M., Gasoline spray characterization and droplets-wall interaction at different piston temperatures. Presented at XXXVIII Meeting of the Italian Section of the Combustion Institute, Lecce, Italy, 2015.

[38] Zeng, W., Sjöberg, M., Reuss, D.L. \& Hu, Z., High-speed PIV, spray, combustion luminosity, and infrared fuel-vapor imaging for probing tumble-flow-induced asymmetry of gasoline distribution in a spray-guided stratified-charge DISI engine. Proceedings of the Combustion Institute, 36, pp. 3459-3466, 2017. 
[39] Köpple, F. et al., Experimental investigation of fuel impingement and spray-cooling on the piston of a GDI engine via instantaneous surface temperature measurements. SAE International Journal of Engines, 7(3), pp. 1178-1194, 2014.

[40] Sirignano, WA., Fluid Dynamics and Transport of Droplets and Sprays. Cambridge University Press, 1999.

[41] Fritsching, U., Spray Simulation. Cambridge University Press, 2004.

[42] Loth, E., Numerical approaches for motion of dispersed particles, droplets and bubbles. Progress in Energy Combustion Science, 26, pp. 161-223, 2000.

[43] Costa, M., Catapano, F., Marseglia, G., Sorge, U., Sementa, P. \& Vaglieco, B.M., Experimental and numerical investigation of the effect of split injections on the performance of a GDI engine under lean operation. SAE Technical Paper, 2015.

[44] Catapano, F., Costa, M., Marseglia, G., Sementa, P., Sorge, U. \& Vaglieco, B.M., Experimental and numerical investigation in a turbocharged GDI engine under knock condition by means of conventional and non-conventional methods. $S A E$ International Journal of Engines, 8(2), 2015.

[45] Costa, M., Sementa, P., Sorge, U., Catapano, F., Marseglia, G. \& Vaglieco, B.M., Split injection in a GDI engine under knock conditions: an experimental and numerical investigation. SAE Technical Paper, 2015.

[46] Teodori, E., Pontes, P., Moita, A.S. \& Moreira, A.L.N., Thermographic analysis of interfacial heat transfer mechanisms on droplet/wall interactions with high temporal and spatial resolution. Experimental Thermal and Fluid Science, 96, pp. 284-294, 2018.

[47] Zhao, P., Hargrave, G.K., Versteeg, H.K., Garner, C.P., Reid, B.A., Long, E.J. \& Zhao, H., The dynamics of droplet impact on a heated porous surface. Chemical Engineering Science, 190, pp. 232-247, 2018.

[48] Kuhnke, D., Spray/Wall-Interaction Modelling by Dimensionless Data Analysis. $\mathrm{PhD}$ thesis, Darmstadt University of Technology: Darmstadt, 2004.

[49] Mundo, C., Sommerfeld M. \& Tropea, C., Droplet-wall collisions: Experimental studies of the deformation and breakup process. International Journal of Multiphase-flow, 21(2), pp. 151-173, 1995.

[50] Khan, S., Panua, R. \& Bose, P.K., Combined effects of piston bowl geometry and spray pattern on mixing combustion and emissions of a diesel engine: A numerical approach. Fuel, 225, pp. 203-217, 2018.

[51] Sforza, L., Lucchini, T. \& Onorati, A., CFD modelling of flame stretch in SI engines. 70th Conference of the ATI Engineering Association, Energy Procedia, 82, pp. 59-66, 2015.

[52] Park, J., Kim, T., Kim, D. \& Park, S., Prediction of wall impingement in a direct injection spark ignition engine by analyzing spray images for high-pressure injection up to $50 \mathrm{MPa}$. Fuel Process Technology, 179, pp. 238-249, 2018.

[53] Chen, W., Pan, J., Liu, Y., Fan, B., Liu, H. \& Otchere, P., Numerical investigation of direct injection stratified charge combustion in a natural gas-diesel rotary engine. Applied Energy, 233-234, pp. 453-467 2019.

[54] Krishna, A.S., Mallikarjuna, J.M. \& Kumar, D., Effect of engine parameters on incylinder flows in a two-stroke gasoline direct injection engine. Applied Energy, 176, pp. 282-294, 2016. 